\title{
Opinion
}

\section{Cannabis Suppression Increases Experimentation \& Legalization}

\author{
Richard Wilmot Ph.D* \\ San Francisco Bay, USA \\ *Corresponding author: Richard Wilmot Ph.D, San Francisco Bay, San Francisco, California, USA \\ Submission: 悳 August 29, 2017; Published: 觜 October 23, 2017
}

\section{Opinion}

The reason why there are now over 20 states allowing medicinal marijuana and some that now legalized it, including California, Colorado, Oregon \& Washington is that in 1988 the DEA's own Administrative Law Judge Francis Young ordered the DEA to move Cannabis from Section One of the Substance Control Act and put it in Schedule Two so that it could be prescribed by a physicians. The DEA ignored his ruling. How could they do this? That's what the States asked too and never got a straight answer. But that is par for the course for the DEA.

When former DEA Chief Leonhart was testifying before the House Judiciary Subcommittee on Crime, Terrorism, and Homeland Security. Polis, a top congressional advocate for marijuana law reform, took the opportunity to grill the DEA administrator on some specifics about marijuana, which has been decriminalized in some parts of his state and legalized for medical purposes in the rest.

"Is crack worse for a person than marijuana?" Polis asked Leonhart.

"I believe all illegal drugs are bad," Leonhart answered. Polis continued, asking whether methamphetamines and heroin were worse for a person's health than marijuana. "Again, all drugs, they're illegal drugs," Leonhart started, before being cut off by polis.

“Yes, no, or I don't know?" Polis said. "If you don't know, you can look this up. You should know this as the chief administrator for the Drug Enforcement Agency. I'm asking a very straightforward question: Is heroin worse for someone's health than marijuana.

Polis... of Colorado...

But aside from that I believe that marijuana makes an excellent aid for psycho therapy and particularly for CBT (Cognitive Behavioral Therapy) by allowing the mix of conscious and unconscious thought with feeling.

Pot does alter mood... that's why people smoke it... it puts one in a state that is neither fully awake nor fully asleep... it's like the state people experience when they are falling asleep at night or waking in the morning... in that dream-like state (not fully awake/not asleep) we are at our most creative as the verbal and non verbal worlds mix and mingle and it is a very pleasurable state with cascades of euphoric feel good chemicals flooding our blood ... many people pray at these times... others experience eroticism... but it is a state in which we would like to stay... at least for awhile... a transient altered state of consciousness... a term that many feel uncomfortable with as they stereotype erratic behavior as solely drug induced.

I can remember graduating from SF State University with a BA... waiting in line to go up onto the stage to get my degree, a hierarchical smile, and an institutional handshake. Since it was Senator Hayakawa, I might have gotten a bow job... but none of us cared. We were passing joints \& smoking pot and our dopamine rushes were much better than we could get from an assembly line ceremony. 